\title{
Transformações na estrutura produtiva global, desindustrialização e desenvolvimento industrial no Brasil
}

\author{
Transformation in the global productive structure, \\ deindustrialization and industrial development in Brazil
}

CÉLIO HIRATUKA

FERNANDO SARTI*

\begin{abstract}
RESUMO: Este artigo tem como principal objetivo destacar as principais transformações da economia global que condicionam o desenvolvimento industrial brasileiro e suas possibilidades de avançar em direção a uma estrutura produtiva mais robusta. Argumenta-se que o debate sobre a desindustrialização no Brasil, embora tenha tido uma importante contribuição para ressaltar a importância da indústria para o desenvolvimento econômico, não aprofundou a discussão sobre os limites e possibilidades de desenvolvimento industrial brasileiro por não considerar adequadamente estas transformações, associadas principalmente ao acirramento da concorrência global e à reorganização das grandes empresas transnacionais.
\end{abstract}

PALAVRAS-CHAVE: desindustrialização; desenvolvimento industrial; indústria brasileira.

ABSTRACT: This paper aims to highlight the major changes in the global economy that affect Brazilian industrial development and mark out the strategies that could move the country toward a more robust productive structure. It is argued that the debate on deindustrialization in Brazil, although it had an important contribution to highlight the importance of manufacturing for economic development, did not deep the discussion about the limits and possibilities of Brazilian industrial development. That debate did not adequately consider those changes in the global economy, related to the more fierce global competition scenario and to the changes in the strategies of Transnational Corporations. KEYWORDS: deindustrialization; industrial development; Brazilian manufacturing. JEL Classification: O1; O5; F6.

\footnotetext{
* Professores do Departamento de Política e História Econômica do Instituto de Economia da Unicamp, e pesquisadores do NEIT/IE/UNICAMP, e-mail celiohiratuka@gmail.com; fersarti64@gmail.com. Submetido: 1/junho/2015; Aprovado: 22/dezembro/2015.
} 


\section{INTRODUÇÃO}

O desenvolvimento industrial brasileiro voltou a ser objeto de um intenso debate nos últimos anos, movimentando um grande conjunto de acadêmicos, instituições empresariais e de trabalhadores, representantes de diferentes esferas governamentais, além da imprensa especializada. Grande parte deste debate tem ocorrido em torno da existência e da intensidade de um processo de desindustrialização na economia brasileira no período recente, assim como do papel da política pública neste contexto.

Este artigo argumenta que, embora tenha sido importante para chamar a atenção para temas importantes, como a reafirmação de que a indústria tem papel-chave no desenvolvimento econômico de um país - seja por suas economias estáticas e dinâmicas de escala, seja por desenvolver e difundir atividades inovadoras - ou de que a taxa de câmbio é uma variável fundamental para sustentar a competitividade industrial, existem aspectos relacionados principalmente às rápidas transformações que vêm ocorrendo na estrutura produtiva global e que ainda não receberam a devida ênfase no debate sobre a desindustrialização no Brasil. Argumenta-se também que essas transformações, tanto por seus aspectos estruturais, quanto pelos seus desdobramentos conjunturais que receberam novo impulso a partir da crise iniciada em 2007-2008, afetam o desenvolvimento da indústria brasileira e condicionam seu futuro. Dessa forma, a compreensão destas mudanças é fundamental e coloca-se como uma precondição para que se possa delinear uma estratégia de desenvolvimento produtivo e tecnológico mais eficaz.

$\mathrm{O}$ artigo está estruturado em três seções, além desta introdução. $\mathrm{Na}$ segunda seção, realiza-se uma breve recuperação sobre as diferentes visões dentro do debate sobre a desindustrialização no Brasil. O objetivo da seção é apresentar uma avaliação sucinta, principalmente para apontar a ausência de elementos associados à reestruturação da estrutura produtiva mundial nessas diferentes visões. A terceira seção busca justamente sistematizar as principais mudanças na atividade produtiva e tecnológica global. A partir da ideia de que as assimetrias produtivas e tecnológicas observadas na economia mundial são uma dimensão-chave para considerar os limites e possibilidades para o avanço das estruturas produtivas dos países em desenvolvimento, busca-se analisar algumas tendências que sofreram mudanças expressivas nos anos recentes e redefiniram estes limites e possibilidades. Finalmente a última seção tece as considerações finais do artigo.

\section{O DEBATE SOBRE A DESINDUSTRIALIZAÇÃO NO BRASIL E SEUS LIMITES}

Como destacado na introdução, a questão da desindustrialização brasileira tem sido um dos temas mais debatidos nos últimos anos, extrapolando inclusive o âmbito acadêmico, sendo discutido em diferentes fóruns e mídias por pesquisadores, empresários, trabalhadores e setores governamentais. 
Mesmo no âmbito estritamente acadêmico, o tema tem sido abordado de diferentes ângulos, com diferentes objetivos e carregando, explícita ou implicitamente, diferentes visões teóricas. Essa diversidade dificulta sistematizar o debate. Porém, sem pretender realizar uma discussão exaustiva, até porque resenhas mais completas sobre o tema podem ser encontradas em outros trabalhos ${ }^{1}$, pretende-se recuperar rapidamente as principais ideias levantadas por um conjunto de autores, apenas para, em seguida, reforçar o argumento de que, apesar da riqueza e do calor da discussão, existem aspectos que têm sido deixados de fora da análise e que são de fundamental importância para destacar os desafios colocados para a indústria brasileira no cenário global, reforçados pelos desdobramentos pós-crise.

Optou-se nesta seção por separar os autores pela sua visão geral sobre o papel da indústria e de sua contribuição para o desenvolvimento econômico, que por sua vez está ancorada em diferentes afiliações teóricas. É importante reconhecer que muitas vezes essa classificação dos autores de acordo com diferentes linhas não é totalmente explícita, e, como em qualquer tentativa de síntese, corre-se o risco de eliminar certas nuances de argumentação. Julgamos, porém, que vale a pena correr o risco da simplificação, em razão da vantagem de organização do debate.

O critério básico utilizado para a apresentação dos autores e de sua avaliação sobre o processo de desindustrialização (ou de industrialização) foi a forma como estes avaliam os processos dinâmicos de mudança estrutural e especialização produtiva, fato que por sua vez está diretamente relacionado à maneira como diferentes enfoques teóricos tratam a contribuição da indústria para o crescimento de longo prazo.

Um primeiro grupo de autores pode ser classificado pela sua aproximação com a visão mais tradicional do mainstream, onde o perfil da especialização setorial não teria influência sobre o crescimento econômico. Essa visão pode ser associada tanto aos modelos neoclássicos tradicionais, onde o crescimento depende da acumulação dos fatores e do progresso técnico, que por usa vez seria exogenamente determinado, quanto aos modelos mais modernos de crescimento endógeno. Nos modelos tradicionais, derivados do trabalho de Solow (1956), mesmo em suas versões mais modernas que buscam ampliar o conceito de capital e incorporar nas funções de produção o estoque de capital humano, a especialização setorial não tem qualquer impacto sobre o crescimento de longo prazo. Já nas novas teorias do crescimento endógeno (Romer, 1990; Grossman e Helpmann, 1991) existe o reconhecimento de que as atividades de P\&D, devido ao seu caráter de bem parcialmente público, podem gerar externalidades positivas. Além disso, pelo fato de apresentar retornos crescentes de escala, permitem explicar endogenamente o crescimento de longo prazo. Neste caso, o crescimento seria específico à atividade de P\&D, mas não ao setor de atividade, ou seja, poderia fazer sentido esti-

\footnotetext{
${ }^{1}$ Ver, por exemplo, Vergnhanini (2013) e Morcero (2012).
} 
mular através da política econômica atividades de P\&D, mas não necessariamente a indústria ou setores industriais específicos.

Entre os trabalhos que podem ser classificados dentro deste primeiro grupo podem ser destacados Bonelli et al. (2013), Bacha (2013) e Pastore et al. (2013).

O trabalho de Bonelli et al. (2013), além de chamar a atenção para a necessidade de correções metodológicas para a análise das series das contas nacionais anteriores a 1995 e a preços constantes, busca situar o Brasil comparativamente a um conjunto de 170 países. Um primeiro fato que chama a atenção é a constatação de que a indústria tem perdido peso em grande parte dos países e regiões, com exceção da Ásia e do Oriente Médio. A partir de análise cross-section para os diferentes países, os autores buscam verificar a participação da indústria brasileira em relação ao previsto pelas regressões, dadas as informações de câmbio real, taxa de poupança, PIB per capita, PIB per capita ao quadrado, população e densidade populacional. Os resultados encontrados pelos autores mostram que, ao longo do tempo, o Brasil passou de uma situação denominada de "doença soviética", isto é, com uma participação da indústria muito superior à norma internacional nas décadas de 1970 e 1980 (mais especificamente até 1987), convergindo para a situação normal entre 1988 e 1993 e passando a ter uma participação da indústria no PIB um pouco inferior ao que seria esperado a partir de então. Ou seja, o movimento que se observa seria apenas uma correção de rota, dado o excesso de industrialização provocado pelo modelo de substituição de importações.

Além disso, em grande medida a causa desse movimento em direção a uma "doença holandesa" moderada, estaria muito mais na escassez da poupança interna, que provocaria uma valorização cambial e um ajustamento estrutural em direção a atividades domésticas (serviços) vis-à-vis as atividades comercializáveis (indústria). O câmbio valorizado seria apenas a manifestação na dimensão preços, da escassez de poupança. Em termos macroeconômicos, a solução estaria em elevar a poupança doméstica e não diretamente na alteração do câmbio. Alternativamente também seria possível uma política microeoconômica, no sentido de elevar a atividade inovativa e os canais para transferência tecnológica, caso se constatasse efetivamente a existência de externalidades positivas dessas atividades na indústria.

O texto de Bacha (2013) analisa o período 2005-2011 e associa a perda da indústria no PIB à combinação de preços de commodities elevados e grande entrada de capitais estrangeiros, possibilitando a elevação do gasto interno acima do PIB. Em uma conjuntura de pleno emprego, a elevação da demanda por bens não comercializáveis acabou resultando em elevação da demanda por mão de obra no setor de serviços. Com o deslocamento da mão de obra para o setor de serviços, ocorreu o fenômeno da desindustrialização.

O trabalho de Pastore et al. (2013) tem um horizonte temporal ainda menor, pois pretende explicar a estagnação da produção industrial a partir de 2010 . De acordo com os autores a explicação estaria associada a um crescimento dos salários reais acima da produtividade. Para esses autores, a expansão da demanda por bens em geral e, em especial, pelo setor de serviços elevou a demanda por mão de obra, pressionando os salários, que, além disso, já vinham crescendo por conta da 
política de valorização do salário mínimo. O contágio da crise internacional e a política de retenção de trabalhadores, dada a situação próxima do pleno emprego, teria acentuado a queda da produtividade, elevando os custos unitários do trabalho. Esta elevação de custos, combinados com o cenário internacional adverso, seria a explicação para a estagnação da produção industrial.

Um segundo grupo de autores pode ser destacado a partir de uma visão que se afasta do mainstream e adota uma visão kaldoriana do crescimento e da especialização produtiva. Para este grupo, o crescimento industrial deveria ser privilegiado, uma vez que é caracterizado por envolver economias estáticas e dinâmicas de escala, concentrar o progresso técnico, apresentar maiores efeitos de encadeamentos sobre os setores a montante e a jusante e apresentar maiores elasticidade-renda da demanda. No entanto, uma vez destacados estes aspectos para justificar a importância da indústria, os autores desta linha focam a análise principalmente nas variáveis macroeconômicas, em especial na taxa de câmbio como elemento fundamental para promover uma estrutura industrial competitiva. Dentro desta corrente, destacam-se os autores denominados novo-desenvolvimentistas.

$\mathrm{O}$ argumento principal destes autores, onde se destacam Bresser-Pereira e Marconi (2008), Bresser-Pereira (2012) e Oreiro e Feijó (2010), é que, em razão da disponibilidade de recursos, países em desenvolvimento acabam tendo vantagens ricardianas, que somadas à entrada de capitais ou às políticas cambiais populistas, voltadas para manter os salários reais artificialmente elevados, inviabilizariam a existência de indústrias competitivas que utilizam tecnologias no estado da arte mundial. A doença holandesa seria caraterizada por uma situação onde haveria uma diferença entre a taxa de câmbio de equilíbrio corrente e a taxa de câmbio de equilíbrio industrial. A "gravidade" da doença holandesa, por sua vez, seria definida pela diferença entre as duas taxas.

De acordo com Bresser-Pereira (2012), a taxa de câmbio estaria no centro da discussão sobre o desenvolvimento industrial, pois funcionaria como uma espécie de interruptor que "ligaria" ou "desligaria" as empresas tecnológicas e administrativamente competentes à demanda mundial. Cabe chamar a atenção aqui para a importância dada à demanda externa, tanto como vetor de dinamismo, mas também como critério de eficiência que deveria balizar as decisões e os instrumentos de política industrial. De acordo com o autor, "No modelo exportador, os países em desenvolvimento tem a possibilidade de usar duas grandes vantagens - mão de obra barata e possibilidade de comprar ou copiar tecnologia disponível. Por sua vez, se o país adota essa estratégia, as autoridades econômicas, que estão fazendo política industrial em favor de suas empresas, passam a ter um critério de eficiência em que se basear: só as empresas eficientes o bastante para exportar serão beneficiadas pela política industrial” (Bresser-Pereira, 2012, p. 19).

Já de acordo com Gala e Libânio (2011), a apreciação da taxa de câmbio teria influência negativa na determinação dos mark-ups dos setores comercializáveis e poderia levar a uma redução dos investimentos destes setores vis-à-vis os setores não comercializáveis. O resultado de uma taxa de câmbio apreciada por um longo período seria a redução da produtividade geral da economia, uma vez que ficaria 
inviabilizado o aumento da produtividade geral através da transferência de recursos para os setores de maior produtividade.

Em termos empíricos, o trabalho de Veríssimo e Xavier (2013), a partir de um modelo de Vetores Autorregressivos e Análise de Decomposição de Variância, apontou para uma influência importante da variação das exportações de commodities sobre a taxa de câmbio real e que estas duas variáveis, juntamente com o preço das commodities, exercem alguma influência sobre o crescimento do PIB.

Interessante observar que as duas correntes anteriores em geral destacam mais os aspectos macroeconômicos que afetam o processo de desenvolvimento industrial. De certa maneira, é possível dizer que o debate sobre a indústria nesse caso estaria "a serviço" de um debate que, em última instância, estaria relacionado ao debate macroeconômico. Este é um aspecto que diferencia os dois primeiros grupos do terceiro, que justamente voltam seu foco para aspectos mais específicos da própria indústria, inclusive dando mais ênfase à evolução que ocorre no interior da indústria e entre seus diferentes setores.

Este terceiro grupo, em grande medida compartilha das mesmas ideias kaldorianas para justificar a importância da atividade industrial, porém acrescenta elementos estruturalistas e neoschumpeterianos na análise, na medida em que dão importância destacada à evolução do perfil setorial dentro da indústria. Parte-se do reconhecimento de que existem padrões setoriais de mudança técnica, que, por sua vez, dependem não apenas da base técnica, mas também das formas de aprendizado e dos diferentes graus de cumulatividade e apropriabilidade das trajetórias tecnológicas. Estas características se traduzem, nos estudos empíricos, em diferentes taxonomias que buscam associar padrões de mudança técnica e inovatividade, a partir, por exemplo, dos trabalhos de Pavitt (1984).

Entre estes trabalhos podem ser destacados IEDI (2007), Nassif (2008), Nassif et al. (2012), Squef (2012) e Morceiro (2012). O trabalho do IEDI destaca a redução da relação entre Valor da Transformação Industrial o Valor Bruto da Produção ${ }^{2}$ em grande parte dos setores industriais entre 1996 e 2006 para destacar as dificuldades da indústria no período. Apesar disso, o estudo aponta uma certa estabilidade na participação dos diferentes grupos de setores classificados por intensidade tecnológica. Da mesma maneira, Nassif (2008) assinalou um perfil de mudança estrutural entre 1991 e 2005 marcado pela manutenção da participação dos setores industriais intensivos em escala e baseados em ciência, embora os setores intensivos em recursos naturais tenham elevado sua participação em detrimento dos setores intensivos em trabalho. Não haveria, portanto, sinais inequívocos de desindustrialização.

No mesmo sentido, o trabalho de Squef (2012) aponta sinais contraditórios de acordo como o indicador utilizado para mensurar o processo de desindustrialização

\footnotetext{
${ }^{2}$ O trabalho de Torres e Da Silva (2012) faz uma análise crítica do indicador VTI/PIB como indicador de agregação de valor, em razão da influência da taxa de câmbio sobre o indicador e da dificuldade de comparação consistente entre diferentes setores.
} 
e de acordo com as fontes de informações. A partir de informações desagregadas setorialmente das Contas Nacionais, da Pesquisa Industrial Mensal (PIM-PF), e do Cadastro Geral de Empregados e Desempregados (CAGED) do Ministério do Trabalho, e observando dados para a produção, emprego e produtividade por intensidade tecnológica, o autor afirma não ser possível concluir pela desindustrialização.

O trabalho de Nassif et al. (2012) utiliza a base de dados PADI (Programa de Análise de Dinâmica Industrial) da CEPAL para avaliar o movimento da indústria brasileira em período mais longo, cobrindo o período 1970-2008. Em relação aos dados de estrutura industrial observa-se uma tendência de aumento do peso dos setores baseados em ciência e engenharia dentro do valor adicionado total da indústria em detrimento dos setores intensivos em mão de obra. Apesar disso, os autores ressaltam que podem ser encontradas evidências de que o Brasil estaria entrando em um processo de desindustrialização precoce em razão do estancamento absoluto da produtividade a partir do final dos anos 1990, do distanciamento relativo em relação à produtividade dos Estados Unidos a partir do mesmo período, do aumento do déficit comercial de setores intensivos em tecnologia e do aumento da elasticidade-renda das importações em ritmo superior ao das exportações.

O trabalho de Morceiro (2012), além de realizar um amplo levantamento dos indicadores de desindustrialização, apresenta avanços em relação aos anteriores por trabalhar com novos indicadores para avaliar a capacidade de geração de encadeamentos dos diferentes setores industriais brasileiros, a partir da utilização das informações da matriz insumo-produto. A partir da análise do coeficiente importado de bens comercializáveis, que trata da parcela dos insumos importados considerando apenas os bens que efetivamente concorrem com bens importados, o autor verificou que ocorreu aumento significativo do indicador, em especial nos setores classificados como de alta e média-alta intensidade tecnológica. Em todos os oito setores classificados desta maneira, o coeficiente importado de bens comercializáveis foi superior a $40 \%$. Observa-se, assim, uma tendência importante de desadensamento produtivo industrial, o que comprometeria a sua capacidade de gerar dinamismo.

A breve análise realizada nesta seção mostra como o debate em torno da desindustrialização tem, em grande medida, organizado a discussão sobre o desenvolvimento industrial no Brasil. Essa discussão teve o mérito de reacender o debate sobre a importância da indústria brasileira para o desenvolvimento econômico e levantar um amplo questionamento sobre a existência ou não do processo, suas causas e consequências, além de permitir avanços nas discussões sobre as diferentes bases de dados e metodologias para mensurar a existência e o grau em que estaria ocorrendo o fenômeno.

Apesar dos avanços, de maneira geral, as análises têm certa dificuldade em incorporar e reconhecer de maneira mais profunda as transformações em curso no sistema produtivo global. Na próxima seção será argumentado que a escala e a intensidade destas mudanças têm redefinido o mapa da produção, do comércio, do investimento e da tecnologia globais, exercendo forças importantes que afetam todos os países com estruturas industriais minimamente diversificadas. O dimen- 
sionamento dos desafios para o desenvolvimento da estrutura produtiva brasileira, para além do debate sobre a existência ou não de um processo de desindustrialização, deve avançar na compreensão destas mudanças.

\section{TRANSFORMAÇÕES NA ESTRUTURA PRODUTIVA GLOBAL}

Como já ressaltado, o principal argumento deste artigo é que o conjunto de transformações concorrenciais, produtivas, tecnológicas e patrimoniais na economia global tem sido de grande magnitude, dificultando a análise dos desafios colocados para a estrutura produtiva brasileira, sem um aprofundamento no entendimento dessas transformações.

Antes porém, de avançar em sua análise, é importante justificar teoricamente essa necessidade. Em primeiro lugar, cabe destacar que, considerando as três visões apresentadas na seção anterior, e a forma como essas visões se desdobram no debate sobre a desindustrialização, julgamos que a terceira é com certeza a mais profícua por incorporar avanços relacionados à análise da mudança técnica e ao papel das inovações no processo de desenvolvimento industrial, assim como por permitir incorporar as diferentes dinâmicas setoriais. No entanto, mesmo nesta terceira abordagem, é necessário explicitar que a forma como o desenvolvimento industrial e tecnológico se projeta na economia global não é uniforme, existindo, portanto, assimetrias e especificidades importantes quando se analisa a inserção dos países em desenvolvimento.

Um ponto de partida interessante para reintroduzir essas questões na discussão é o proposto por Cassiolato e Lastres (2005) e Guimarães et al. (2007), a partir da aproximação teórica entre a literatura neoschumpeteriana, em especial a que centra a análise nos Sistemas Nacionais de Inovação (SNI) e o estruturalismo latino-americano.

A literatura sobre os $\mathrm{SNI}^{3}$ enfatiza que o desempenho industrial e inovativo depende não apenas da performance individual de empresas e organizações de ensino e pesquisa, mas também das formas como elas interagem entre si e com vários outros atores e instituições. Refletem, portanto, condições culturais e institucionais locais historicamente construídos, que orientam o processo de aprendizado. Esta literatura também chama a atenção para o caráter cumulativo do aprendizado. Neste sentido, existem barreiras que impedem a transmissão e reprodução pura e simples de conhecimento criado nos países centrais pelos países em desenvolvimento.

Tanto Cassiolato e Lastres (2005) quanto Guimarães et al. (2007) destacam que esta abordagem é compatível e convergente com um dos aspectos centrais do estruturalismo latino-americano, que é o reconhecimento das condições assimétri-

\footnotetext{
${ }^{3}$ As referências fundamentais pioneiras dentro desta abordagem são os trabalhos de Lundvall (1992), Nelson (1993) e Freeman (1995).
} 
cas de que partem os países em desenvolvimento da região, perante os países centrais. Uma das marcas do pensamento estruturalista é o reconhecimento do papel do progresso técnico como motor da dinâmica capitalista, porém, sujeito a projeções globais diferenciadas. Essas assimetrias internacionais econômicas e tecnológicas podem se aprofundar principalmente pelas assimetrias também existentes em relação ao acesso ao conhecimento e ao aprendizado. De acordo com Guimarães et al. (2007), "mais importante do que as assimetrias tecnológicas, são as assimetrias que implicam a impossibilidade de acessar, compreender, absorver, dominar, usar e difundir conhecimento" ( p. 217).

Como enfatizado por Chesnais $(1996,2013)$, essas assimetrias estão condicionadas em grande medida pela forma como o processo de concorrência ultrapassa as fronteiras nacionais e se modifica a partir da interação entre as estratégias dos grandes oligopólios (crescentemente globais) e as políticas dos Estados Nacionais. A compreensão dos limites e possibilidades do desenvolvimento industrial e tecnológico nos países em desenvolvimento não pode prescindir, portanto, de analisar de maneira mais aprofundada as mutações na estrutura produtiva e tecnológica mundial, para buscar entender de que forma a estrutura produtiva doméstica interage com essas transformações. Não se trata, contudo, de negar a importância de fatores internos, mas sim, como destacado por Tavares (1985) em seu estudo clássico sobre a industrialização brasileira, de entender que as estratégias dos oligopólios globais e das Empresas Transnacionais (ETN) não determinam exogenamente a dinâmica de acumulação dos países em desenvolvimento, mas se articulam com ela e a modificam a partir de dentro

Neste sentido, Chesnais (Ibid.) tem enfatizado que, desde as últimas décadas do século passado, estas estratégias têm alterado de maneira importante o mapa da produção, do comércio, dos investimentos, das finanças e do conhecimento tecnológico em nível global.

A partir dessa perspectiva, serão destacadas a seguir quatro tendências que julgamos fundamentais para organizar a análise das transformações que vêm ocorrendo na estrutura produtiva global nos últimos anos. Com poderá ser visto, essas transformações estão inter-relacionadas, porém optou-se por apresentá-las de maneira separada para maior clareza na exposição de cada uma delas. A primeira diz respeito à reorganização das estratégias globais de organização da atividade produtiva por parte das ETN e como isso afetou as possibilidades de desenvolvimento industrial. A segunda está associada ao surgimento da China como grande fornecedora mundial de produtos manufaturados. A terceira diz respeito à continuidade da concentração no domínio de conhecimento tecnológico por parte das grandes ETN. Finalmente, a quarta refere-se ao recente lançamento de políticas ativas por parte de diversos países para recuperar sua atividade industrial e fomentar a inovação em novas áreas e setores econômicos.

Em relação às estratégias globais das ETN, a mudança na gestão e nas formas de operação internacional foi alavancada pelas estratégias das corporações americanas, pressionadas pela competição acirrada levada a cabo por empresas da Europa Continental e do Japão. Vale lembrar que no período do pós-guerra, a partir 
de um parque industrial renovado e de políticas industriais ativas, principalmente as empresas da Alemanha e do Japão passaram rapidamente a desafiar a superioridade das grandes empresas americanas. No caso do Japão, a estrutura organizacional mais flexível e com maior capacidade de organizar e coordenar as relações intra e interfirmas para o aprendizado e a inovação representou uma vantagem importante, dado o cenário típico de instabilidade prevalecente a partir dos anos 1970 (Imai, 1990).

De outro lado, a grande empresa americana encontrou-se pressionada também pelo crescente questionamento acerca da eficiência do modelo gerencial da grande corporação multidivisional diversificada. Para os críticos desse modelo, a autonomia exagerada dos gerentes para alocar os lucros acumulados havia criado corporações excessivamente diversificadas, com a implementação de projetos de investimentos que não necessariamente geravam retornos aos acionistas, resultando em perda de eficiência e competitividade internacional. Acionistas mais ativos, remunerações atreladas ao desempenho das ações e o movimento de fusões e aquisições hostis seriam as formas de disciplinar e implementar um novo modelo de gestão, mais alinhado com o interesse dos acionistas, nessas grandes corporações ${ }^{4}$.

Esse processo resultou em um profundo processo de reestruturação, com a tentativa de aliar a acumulação de ativos intangíveis com movimentos de racionalização e busca por flexibilidade, de maneira a responder ao mesmo tempo à pressão competitiva, à maior instabilidade das variáveis macroeconômicas e às exigências de retorno mais elevado e rápido derivados da crescente pressão do mercado financeiro sobre a gestão corporativa.

Do ponto de vista da estrutura produtiva e da organização das atividades econômicas, observou-se uma intensa desverticalização, com a fragmentação de atividades acompanhadas por uma intensa transferência internacional de etapas produtivas, de maneira a aproveitar as possibilidades de redução de custos, acompanhados dos ganhos de economias de escala e escopo, viabilizadas pela ampliação dos mercados e pela gestão coordenada de atividades geograficamente dispersas. O processo de produção passou a ocorrer crescentemente sob a forma de uma rede internacional, integrando diferentes países e diferentes empresas, realizando etapas da cadeia de valor sob a coordenação das grandes corporações. ${ }^{5}$

Vale destacar que, neste novo contexto, a articulação entre produção, exportação de manufaturas e desenvolvimento industrial e econômico mudou significativamente. Como destacado por Baldwin (2011), a incorporação de atividades industriais por parte dos países em desenvolvimento passou a ser muito mais fácil,

\footnotetext{
${ }^{4}$ Ver Jensen (1989) para os fundamentos desse novo modelo de gestão e Aglietta e Riberieux (2005) e Lazzonick e O'Sullivan (2000) para um visão crítica.

${ }^{5}$ Este movimento foi capturado pela literatura de organização industrial e de economia internacional de diversas maneiras e com diferentes denominações. Ver, entre outro, Sturgeon (2002), Gereffi et al. (2005), UNCTAD (2013) e OECD, WTO e UNCTAD (2013).
} 
uma vez que se tornou possível realizar etapas produtivas manufatureiras específicas, mesmo aquelas para as quais praticamente o único requisito necessário é o baixo custo de mão de obra. Antes do advento das redes globais de produção, essa incorporação exigia a internalização de cadeias produtivas inteiras e, muitas vezes, um conjunto de cadeias produtivas complementares, o que significava uma necessidade grande de mobilizar recursos financeiros, humanos, técnicos, gerenciais e tecnológicos. Além disso, demandava grande capacidade de coordenar os investimentos e a criação de capacitações em todos estes aspectos. Industrialização era sinônimo da criação e montagem desta estrutura. No novo contexto, passou a ser possível atrair etapas específicas da cadeia de valor, dado a redução das barreiras para o início da atividade manufatureira, assim como para as exportações de produtos manufaturados. Ou seja, nos termos de Baldwin, se tornou possível internalizar atividades manufatureiras através da inserção em etapas da cadeia de valor, enquanto no passado era necessário criar essas cadeias de valor internamente. Mas, ao mesmo tempo em que a incorporação de atividades manufatureiras se tornou mais fácil, seus impactos e seu significado do ponto de vista do desenvolvimento econômico podem ser muito menores, uma vez que, a depender do tipo de atividade internalizada, da magnitude dos efeitos de encadeamentos, do processo de aprendizado e dos transbordamentos, pode ocorrer criação de capacidade manufatureira sem necessariamente ocorrer industrialização.

Dentro deste contexto, é possível entender melhor o intenso deslocamento da atividade industrial em direção aos Países em Desenvolvimento (PED) e a emergência da região asiática, em especial a China, como grande centro mundial produtor de manufaturas. O dinamismo industrial do Leste Asiático, por sua vez, foi em grande medida alavancado pela emergência da China como potência industrial, que é justamente a segunda tendência a ser analisada nesta seção.

De acordo com dados da UNIDO (2011), a China representava em 1980 cerca de $1,4 \%$ do valor adicionado manufatureiro e $1 \%$ das exportações globais. Em 2010 , esses indicadores passaram a $15,4 \%$ e $10,3 \%$, respectivamente. A economia chinesa soube aproveitar o movimento de deslocamento de atividades manufatureiras ocorrido ao longo dos anos 1980 e 1990 para alavancar seu processo de desenvolvimento industrial, inicialmente com as etapas mais simples do processo de montagem dentro das cadeias das ETN, mas avançando rapidamente para etapas mais complexas e com participação crescente de empresas nacionais e estatais (Haley e Haley, 2013).

O nível de desenvolvimento econômico atingido pela China, refletido também em suas elevadas escalas de produção e consumo, tem posicionado o país não apenas como um grande produtor de manufaturas industriais, mas também como um grande importador de insumos e matérias-primas industriais e de bens de capital, além de crescente consumidor de manufaturas, alimentos e matérias-primas minerais e energéticas. Embora o efeito do crescimento chinês sobre o aumento de preço de commodities seja o fato mais enfatizado, existem outros dois aspectos, mais diretamente ligados à produção industrial que devem ser destacados.

A incorporação de um amplo contingente de mão de obra de baixo custo aos 
processos de produção em rede voltadas para o mercado internacional, aumentando ao mesmo tempo a escala de produção e o número de produtores nas etapas menos complexas da cadeia, vem reduzindo de maneira acentuada o preço mundial de alguns produtos manufaturados, principalmente computadores e semicondutores, mas também em outros setores. Esse efeito pode ser visualizado, tomando-se os índices de preços das importações dos Estados Unidos como proxy do preços internacionais. É possível perceber, através do Gráfico 1, que os preços de importações de bens de capital tiveram uma redução de $20 \%$, os equipamentos de telecomunicações, $30 \%$, e os computadores e semicondutores, $70 \%$.

Gráfico 1: Índice de Preços de Importações dos Estados Unidos (1994 =100).

Setores selecionados. 1994 a 2012.

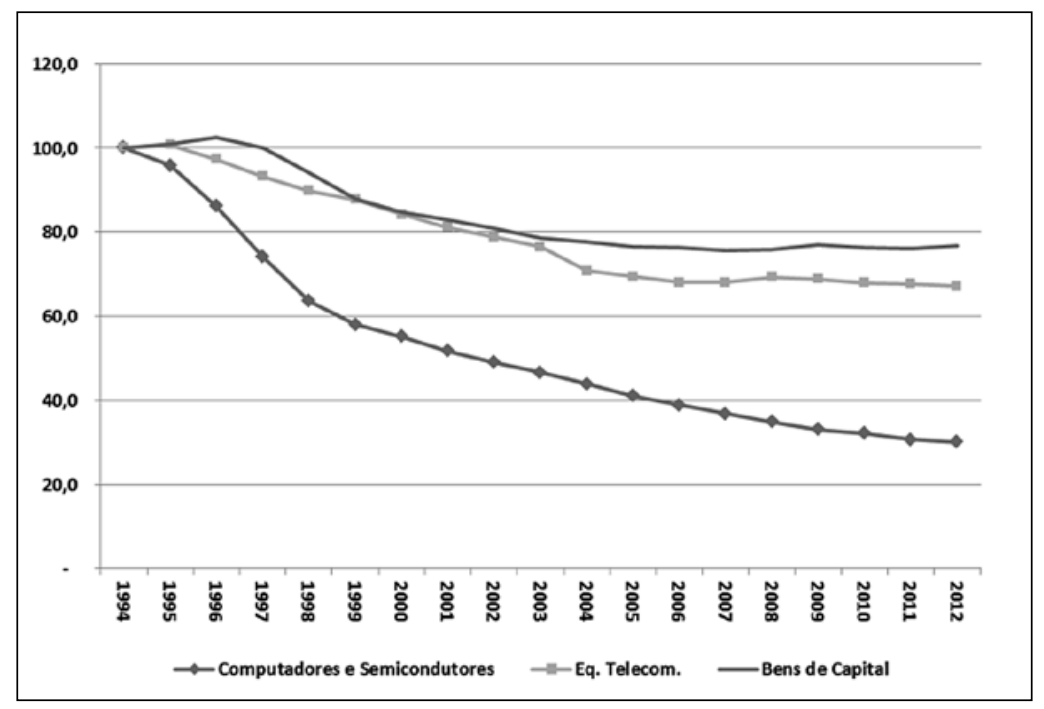

Fonte: US Bureau of Labor Statistics.

O segundo efeito diz respeito ao extraordinário aumento de capacidade de produção manufatureira em várias indústrias voltadas ainda para o mercado interno chinês, mas que podem aumentar ainda mais os impactos sobre a indústria mundial caso sejam mais direcionadas ao mercado internacional. Um exemplo é a indústria de aço, onde a produção chinesa correspondeu a $47 \%$ da produção mundial em 2012 de acordo com a World Steel Association. Apenas a adição de capacidade da China em 2012, correspondeu a 119 milhões de toneladas, o que representou mais do que toda a produção do Japão (segundo maior produtor mundial, com 107 milhões de toneladas) no mesmo ano e cerca de 3,5 vezes a produção total do Brasil (9- maior produtor). Outro exemplo ocorre na indústria automotiva, onde, de acordo com a OICA (International Organization of Motor Vehicles Manufacturers), a produção de 18 milhões de automóveis de passageiros na China respondeu, em 2013 , por $27 \%$ da produção mundial e foi maior do que a produção somada dos três maiores produtores seguintes no ranking (Japão, Alemanha e Estados Unidos). 
Ou seja, o estabelecimento de um conjunto de produtores asiáticos, liderados pela China, ao mesmo tempo em que elevou a demanda por diferentes commodities e insumos básicos, tem criado uma competição extremamente acirrada nos mercados de produtos manufaturados e que futuramente pode aumentar ainda mais. Vale destacar que o crescimento elevado e sincronizado da economia global entre 2003 e 2008 acentuou o primeiro aspecto e atenuou o segundo. $\mathrm{O}$ período posterior à crise, por outro lado, atenuou o primeiro fenômeno e acentuou o segundo.

A terceira tendência está relacionada a um aspecto bastante importante e muitas vezes negligenciado na literatura sobre cadeias globais de valor. Apesar do surgimento de novos competidores e da abertura de espaços seletivos para a inserção dos países em desenvolvimento dentro das redes de produção, este movimento não significou uma mudança nos oligopólios globais na direção de uma redução generalizada das barreiras à entrada, com uma consequente maior facilidade para implementar estratégias de catching-up por parte de empresas e indústrias dos países em desenvolvimento.

Em que pese a abertura de espaços em etapas específicas da atividade manufatureira em várias cadeias produtivas para empresas de países em desenvolvimento, o processo de descentralização produtiva não significou necessariamente possibilidade de redução de assimetrias competitivas. Pelo contrário, as grandes empresas, ao mesmo tempo em que se desfaziam de atividades fora do core business consideradas não essenciais, mesmo na manufatura, buscaram reforçar seus ativos intangíveis, aumentar o controle sobre padrões tecnológicos e adquirir ativos de concorrentes estratégicos através de um processo intenso de fusões e aquisições (Chesnais, 1996; Dedrick et al., 2009). A elevação do poder de comando das grandes corporações dos países centrais sobre o valor gerado nas diferentes regiões foi potencializado e o aumento da escala global passou a ser um fator fundamental na luta competitiva, resultado das vantagens associadas à capacidade de diversificar riscos, operar em vários mercados, explorar diferenciais de custos e vantagens de localização em diferentes regiões.

Assim, por um lado, a crescente internacionalização, mensurada por dados de comércio, investimento e produção manufatureira, mostra sinais de crescente participação de países em desenvolvimento, embora de um conjunto relativamente restrito de países. Por outro, as informações sobre a capacidade de comando através de redes de propriedade das grandes corporações globais apontam para um processo de maior concentração e centralização do capital.

Quando se observam os dados de internacionalização das atividades tecnológicas das ETN, que justamente conferem a estas empresas a capacidade para absorver grande parte do valor criado ao longo dessas cadeias globais, também se observa uma situação de grande concentração (Miranda, 2014). Em relação a esse último aspecto vale destacar que os gastos em P\&D permanecem muito concentrados nos países desenvolvidos e dominados por um grupo reduzido de ETN. Como pode ser visto na Tabela 1 , considerando as informações das 1.500 maiores empresas em termos de gastos em P\&D, estas foram responsáveis por cerca de 
$45 \%$ dos gastos mundiais (inclusive os realizados fora do setor privado) em 2011. Considerando apenas as 100 maiores, estas representaram cerca de 1/4 do total global e quase $60 \%$ das 1.500 maiores.

Tabela 1: Gastos de P\&D das maiores companhias globais e participação no P\&D global em 2011. Em €\$ milhões e \%.

\begin{tabular}{cccc}
\hline TOP & $\begin{array}{c}\text { Gastos de } \\
\text { P\&D Acumulados }\end{array}$ & $\begin{array}{c}\text { Participação } \\
\text { nas } \\
\text { TOP 1.500 }\end{array}$ & $\begin{array}{c}\text { Participação no } \\
\text { P\&D } \\
\text { Global }\end{array}$ \\
\hline 50 & 214.884 & $42,0 \%$ & $19,2 \%$ \\
100 & 291.276 & $57,0 \%$ & $26,0 \%$ \\
250 & 384.150 & $75,2 \%$ & $34,3 \%$ \\
500 & 441.296 & $86,3 \%$ & $39,4 \%$ \\
1000 & 488.015 & $95,5 \%$ & $43,5 \%$ \\
1500 & 511.156 & $100,0 \%$ & $45,6 \%$ \\
\hline
\end{tabular}

Fonte: EU Industrial Scoreboard e National Science Foundation

A Tabela 2 apresenta dados sobre a distribuição de patentes depositadas por empresas no European Patent Office (EPO), por país de localização do depositante segundo os subperíodos 1980-1989, 1990-1999 e 2000-2009. ${ }^{6}$ No primeiro caso, nos três subperíodos, houve elevada concentração nos países da tríade, dentre os quais se destacam EUA, Japão, Alemanha e França.

Tabela 2: Patentes depositadas no EPO, por país de origem do depositante. Em \% do total

\begin{tabular}{l|c|c|c}
\hline \multicolumn{1}{c|}{ País/Região } & $1980-1989$ & $1990-1999$ & $2000-2009$ \\
\hline Países desenvolvidos & 99,81 & 98,89 & 94,58 \\
EUA & 31,76 & 32,16 & 26,56 \\
Japão & 25,33 & 24,61 & 23 \\
Alemanha e França & 23,48 & 22,83 & 23,45 \\
Europa - Outros* & 18,6 & 18,14 & 19,7 \\
OECD - Outros** & 0,64 & 1,15 & 1,87 \\
Países em desenvolvimento & 0,14 & 1 & 5,24 \\
Ásia (selecionados) & 0,06 & 0,88 & 5,03 \\
Coreia do Sul & 0,02 & 0,72 & 3,53
\end{tabular}

\footnotetext{
${ }^{6}$ A Tabela 1 apresenta os resultados para todos os países que tiveram patente atribuída no período 1980-2009. Além disso, para captar as atividades de patenteamento associada às ETNs foi feito um filtro para eliminar patentes depositadas por pessoas físicas, institutos de pesquisa, universidades e agências governamentais. Para maiores detalhes, ver Miranda (2014).
} 


\begin{tabular}{l|c|c|c} 
China & 0 & 0,01 & 0,76 \\
\hline Taiwan & 0,01 & 0,07 & 0,41 \\
Índia & 0 & 0,03 & 0,22 \\
Cingapura & 0 & 0,03 & 0,08 \\
Malásia & 0 & 0 & 0,01 \\
Hong Kong & 0,02 & 0,02 & 0,01 \\
Outros PEDs & 0,08 & 0,12 & 0,21 \\
Brasil & 0,01 & 0,05 & 0,1 \\
Rússia & - & 0,01 & 0,02 \\
México & 0 & 0,01 & 0,03 \\
Arábia Saudita & - & 0,01 & 0,03 \\
África do Sul & 0,07 & 0,06 & 0,04 \\
Argentina & - & 0 & 0 \\
Outros & 0,05 & 0,11 & 0,17 \\
\hline Total (\%) & 100 & 100 & 100 \\
\hline No total de patentes & 234.569 & 497.159 & 835.201 \\
\hline Fon: Miras
\end{tabular}

Fonte: Miranda (2014), a partir de dados de EPO PATSTAT / EPO e Orbis / BvD.

Notas: " Em "Europa - Outros" estão agregados 22 países: Áustria, Bélgica, Suíça, República Tcheca, Dinamarca, Espanha, Finlândia, Reino Unido, Grécia, Hungria, Irlanda, Islândia, Itália, Luxemburgo, Países Baixos, Noruega, Polônia, Portugal, Suécia, Eslovênia, Eslováquia e Turquia.

"“Em "OECD - Outros" estão agregados quatro países: Austrália, Canadá, Israel e Nova Zelândia.

Embora suas participações tenham mostrado pequena queda entre o primeiro e o último subperíodo, na década de 2000 , as ETN originárias desses quatro países foram responsáveis por mais de $70 \%$ do total de patentes depositadas. Considerando o conjunto das empresas sediadas nos países desenvolvidos, o total chega a mais de $94,5 \%$ do total de patentes no último subperíodo.

Finalmente, a última tendência, desta vez mais associada ao cenário pós-crise, é o reforço das políticas nacionais de incentivo à mudança tecnológica e à reestruturação industrial como forma de recuperar dinamismo econômico, em especial nos países centrais.

Nos Estados Unidos, por exemplo, os trabalhos de Pisano e Shih (2012), Sperling (2013) e Berger (2013) enfatizam que muitas vezes a inovação só consegue avançar de maneira efetiva quando é colocalizada com um conjunto de atividades que inclui a atividade manufatureira. Reconhecem que o movimento de externalização da manufatura talvez tenha ido longe demais e ressaltam a necessidade de reforçar o ecossistema de produtores, fornecedores, instituições de pesquisa e de formação de mão de obra, com o objetivo de acelerar a geração de produtos e processos inovadores.

Dessa maneira, ao mesmo tempo em que a política estadunidense busca reforçar os laços entre manufatura e inovação, também aponta para apoio mais robusto à pesquisa científica em novas plataformas tecnológicas. Em documento 
oficial do governo dos Estados Unidos (National Economic Council, Council of Economic Advisers, and Office of Science and Technology Policy, 2011), é mencionada a necessidade de acelerar inovação nas seguintes áreas: energia limpa, biotecnologia, nanotecnologia e manufatura avançada, tecnologias educacionais, tecnologias para saúde, aeroespacial.

Também no caso da União Europeia verifica-se a mesma preocupação em apoiar a atividade industrial, explícita por exemplo no Comunicado da Comissão Europeia sobre Política Industrial (2012) e em Veugelers (2013). Além das ações de apoio à competitividade industrial, o comunicado menciona seis áreas prioritárias para fomentar a inovação: sistemas de tecnologia avançada para produção limpa, construção sustentável, tecnologias-chaves de comunicação e informação habilitadoras, veículos sustentáveis, produtos bio-based e smart grids.

Finalmente, é importante destacar que a China também tem avançado rápido na direção de endogeneizar capacidade inovativa e aumentar o peso das atividades intensivas em conhecimento, consubstanciada em seu Plano de Médio e Longo Prazo para o Desenvolvimento de Ciência e Tecnologia (2006-2020) e no $12^{\circ}$ Plano Quinquenal (2011-2015) (Lazzonick e Li, 2012).

\section{CONSIDERAÇÕES FINAIS}

A análise realizada ao longo deste artigo procurou argumentar que, apesar do caloroso debate em torno da questão da desindustrialização no Brasil, existem importantes aspectos associados às mudanças observadas na economia mundial que ficaram de fora deste debate. A importância de melhor compreender essas mudanças reside no fato de que a sua profundidade as torna elementos fundamentais e necessários para discutir uma estratégia mais ampla de desenvolvimento da estrutura produtiva brasileira.

A intensificação da concorrência em nível global significou para as empresas líderes uma estrutura mais flexível e mais focada no domínio e controle sobre ativos intangíveis, ao mesmo tempo em que parte considerável das atividades produtivas mais commoditizadas foram segmentadas, externalizadas e transferidas para países em desenvolvimento, especialmente na região asiática. A combinação dessas estratégias com políticas ativas de desenvolvimento por parte de alguns destes países, com destaque para a China, criou um ambiente onde surgiram novos competidores com capacitações produtivas e manufatureiras diferenciadas para produção com baixo custo em diversos setores e etapas das cadeias produtivas, ao mesmo tempo em que as empresas líderes globais dos países centrais acentuam seu esforço para desenvolver, adquirir e dominar os ativos-chave, capazes de manter o comando sobre as cadeias de valor internacionais, reforçando barreiras à entrada nessa dimensão superior.

Coloca-se, portanto, a dificuldade de enfrentar uma competição em custo bastante acirrada, liderada pela produção chinesa, mas que envolve outros produtores asiáticos, que combinam custos de mão de obra, escala, câmbio, e incentivos 
governamentais bastante potentes. De outro lado, a competição é reforçada pelas empresas líderes dos oligopólios globais que lançam mão de seu escopo mundial para reforçar ativos, em especial os intangíveis, como marcas, canais de comercialização e capacitações tecnológicas, capazes de comandar cadeias de valores globais, com maior flexibilidade em seu comprometimento de recursos.

Esse ambiente de concorrência acirrada se tornou ainda mais feroz depois do início da crise global em 2007-2008. O lento crescimento da demanda mundial a partir de então tem tornado a busca por mercados e a necessidade de ocupação de capacidade uma alavanca poderosa para estimular a competição e a mobilização de vários instrumentos para a conquista de market-share por parte de empresas e países. Além disso, uma das consequências da crise foi a crescente discussão dentro de diferentes países sobre a necessidade de retomar de maneira mais firme a capacidade de produção manufatureira e o avanço da inovação em áreas consideradas estratégicas. Os países centrais, em especial, buscam estimular o desenvolvimento de novos setores, mercados e áreas tecnológicas.

O desafio que está colocado, portanto, vai além do que se estabelece apenas a partir do debate estrito sobre a desindustrialização no Brasil. Espera-se que este texto tenha conseguido chamar a atenção para o fato de que o novo cenário global vai exigir um esforço redobrado de avaliação da posição relativa do país ante as transformações nos vários setores e cadeias produtivas mundiais, das capacitações existentes e potenciais no sistema produtivo nacional, assim como da adequação ou não dos instrumentos e da institucionalidade presente hoje dentro da política industrial, científica e tecnológica para fazer frente a este cenário desafiador.

\section{REFERÊNCIAS BIBLIOGRÁFICAS}

AGLIETTA, M. e RIBERIOUX, A (2005). Corporate Governance adrift. Acritique of Shareholder Value. Londres: Edward Elgar.

BACHA, E. (2013) “Bonança externa e desindustrialização. Uma análise do período 2005-2011”. In: BACHA, E.; BOLLE, M. (Org.). O Futuro da Indústria no Brasil: Desindustrialização em Debate. Rio de Janeiro: Civilização Brasileira.

BERGER, S. (2013) Making in America. Cambridge: MIT Press.

BALDWIN, R. (2011) “Trade And industrialisation after globalisation's 2nd unbundling: how building and joining a supply chain are different and why it matters”. NBER Working Paper, $\mathrm{n}$. W17.716.

BONELLI, R.; PESSOA, S. A. MATOS, S. (2013) "Desindustrialização no Brasil: fatos e interpretação". In: BACHA, E.; BOLLE, M. (Org.). O Futuro da Indústria no Brasil: Desindustrialização em Debate. Rio de Janeiro: Civilização Brasileira.

BRESSER-PEREIRA, L. C. (2012) "A taxa de câmbio no centro da teoria do desenvolvimento". Estudos Avançados 26 (75).

BRESSER-PEREIRA, L. C.; MARCONI, N. (2008) “Existe doença holandesa no Brasil?” Anais do IV Fórum de Economia de São Paulo, São Paulo: Fundação Getúlio Vargas.

CASSIOLATO, J.E., LASTRES, H. (2005) "Sistemas de inovação e desenvolvimento: as implicações de política”. São Paulo em Perspectiva, v. 19, n. 1, p. 34-45, jan./mar.

CHESNAIS, F. (1996) A Mundialização do Capital. São Paulo: Xamã.

CHESNAIS. F. (2013) "Present international patterns of foreign direct investment: underlying causes and some policy implications for Brazil”. Revista de Economia Contemporânea, vol. 17, n. 3. 
DEDRICK, J., KRAEMER L. K. E LINDEN, G. (2009) "Who profits from innovation in global value chains?: a study of the iPod and notebook PCs.” Industrial and Corporate Change, vol. 19:1.

EUROPEAN COMISSION (2012). Industrial Policy Communication 2012. A Stronger European Industry for Growth and Economic Recovery. Disponível lem http://eur-lex.europa.eu/legal-content/EN/TXT/PDF/?uri=CELEX:52012DC0582\&from=EN

FREEMAN, C. (1995) "The national system of innovation in historical perspective". Cambridge Journal of Economics, v. 19, n. 1, p. 5-24.

GALA, P. e LIBÂNIO, G. (2011) "Taxa de câmbio, poupança e produtividade: impactos de curto e longo prazo”. Economia e Sociedade. Vol. 20. N. 2 (42). PP. 229-242.

GEREFFI, G., STURGEON, T. e HUMPRHEY, J. (2005) “The governance of global value chains”. Review of International Political Economy, 12:1.

GROSSMAN, G. M., Helpman, E. (1991) Innovation and Growth in the Global Economy. Cambridge, MA: M.I.T. Press.

GUIMARÃES, V., PEIXOTO, F., CASSIOLATO, J.E e LASTRES, H. (2007) “Convergências e complementaridades da corrente neo-schumpetriana com o pensamento estruturalista de Celso Furtado". In SABOIA, J. e CARDIM DE CARVALHO, F. (orgs). Celso Furtado e o século XXI. Baureri: Manole e Rio de Janeiro: IE/UFRJ.

HALEY, U.C.V e HALEY, G.T. (2013) Subsidies to Chinese Industry: State Capitalism, Business Strategy and Trade Policy. New York: Oxford University Press.

IEDI. (2007) Desindustrialização e os Dilemas do Crescimento Econômico Recente. São Paulo, IEDI.

IMAI, K. (1990) "Patterns of innovation and entrepreneurship in Japan". In Arnold Heertje und Mark Perlman (orgs) Evolving Technology and Market Structure, Studies in Schumpeterian Economics. Ann Arbor, MI: University of Michigan Press, 187-202.

JENSEN, M. (1998) “O eclipse do grupo empresarial de capital aberto”. In Montgomery, C. e Porter, M.(orgs.) Estratégia. Rio de Janeiro: Campus.

LAZONICK, W. e O'SULLIVAN, M. (2000) "Maximizing shareholder value: a new ideology for corporate governance". Economy and Society, vol.29 n.1.

LAZZONICK, W. e LI, Y. (2012) China's Path to Indigenous Innovation. Cambridge: Sase Conference Paper.

LUNDVALL, B-Å (Ed.) (1992) National Innovation Systems: Towards a Theory of Innovation and Interactive Learning. London: Pinter.

MIRANDA, P. C. (2014) “A internacionalização das atividades tecnológicas e a inserção dos países em desenvolvimento: uma análise baseada em dados de patentes". Tese de Doutorado. IE/UNICAMP.

MORCEIRO, P. C. (2012) "Desindustrialização na economia brasileira no período 2000-2011: abordagens e indicadores”. Dissertação de Mestrado em Economia - Universidade Estadual Paulista, Faculdade de Ciências e Letras, Araraquara.

NASSIF, A. (2008) "Há evidência de desindustrialização no Brasil?" Revista de Economia Política. v. $28, \mathrm{n}^{\circ} 1$, jan/mar., pp. 72-96.

NASSIF, A.; FEIJÓ, C. e ARAÚJO, E. (2012) Structural change and economic development: is Brazil catching up or falling behind?. Porto de Galinhas, Anais do 40o. Encontro da ANPEC.

NATIONAL ECONOMIC COUNCIL, Council of Economic Advisers, and Office of Science and Technology Policy (2011) A strategy for American Innovation. Washington: White House.

NELSON, R. (ed.) (1993). National Innovation Systems. A Comparative Analysis. Oxford: Oxford University Press.

OECD, WTO e UNCTAD. (2013) Implications of Global Value Chains for trade, investment, development and job. Paper prepared for the G-20 Leader Summit. Disponível em http://www.oecd.org/ trade/G20-Global-Value-Chains-2013.pdf

OREIRO, J. L. e FEIJÓ, C. A. (2010) "Desindustrialização: conceituação, causas, efeitos e o caso brasileiro" Revista de Economia Política, vol. 30, n 2 (118), abr./jun.

PASTORE, A. C; GAZZANO, M.; PINOTTI, M. C (2013) "Por que a produção industrial não cresce desde 2010? "In: BACHA, E.; BOLLE, M. (Org.). O Futuro da Indústria no Brasil: Desindustrialização em Debate. Rio de Janeiro: Civilização Brasileira. 
PAVIIT, K. (1984) Sectoral Patterns of Technical Change: Towards a Taxonomy and a Theory Research Policy (13). North Holland.

PISANO, G. e SHIH, W. (2012) Producing Prosperity: Why America Needs a Manufacturing Renaissance. Cambridge: Havard Business School Press.

ROMER, P. M. (1990) “Endogenous technological change”. Journal of Political Economy, 98(5), 71-102.

SOLOW, R.M. (1956) "Contribution to the theory of economic growth". Quarterly Journal of Economics, 70(1), 65-94.

SPERLING, G. (2013) . The Case for a Manufacturing Renaissance. Texto disponível em http://www. whitehouse.gov/sites/default/files/docs/the_case_for_a_manufacturing_renaissance_gene_sperling_7-25-2013_final_p....pdf

SQUEFF, G.C. (2012) “Desindustrialização: luzes e sombras no debate brasileiro”. IPEA.Texto para Discussão, n. 1747. Brasilia, jun.

STURGEON, T. (2002) "Modular production networks: a new American model of industrial organization”. Industrial and Corporate Change, vol. 11, n. 3. 2002.

TAVARES, M. C. (1985) Acumulação de Capital e Industrialização no Brasil. Editora da UNICAMP.

TORRES, R. L; DA SILVA, H.C. (2012) Uma crítica aos indicadores usuais de desindustrialização no Brasil. Porto de Galinhas: Anais do $40^{\circ}$. Encontro da ANPEC.

UNCTAD (2013) World Investment Report. Global Value Chains: Investment and trade for development. Nações Unidas: Nova York e Geneva.

UNIDO (2011) Industrial and Development Report. Viena: UNIDO.

VERGNHANINI, R. (2013) O debate sobre a mudança estrutural da economia brasileira nos anos 2000. Dissertação de Mestrado. UFRJ, Rio de Janeiro.

VERÍSSIMO, M. P. e XAVIER, C. L. (2013) "Taxa de câmbio, exportações e crescimento: uma investigação sobre a hipótese de doença holandesa no Brasil”. Revista de Economia Política, vol. 33, n ${ }^{\circ}$ 1 (130), pp. 82-101, janeiro-março.

VEUGELERS, R. (2013) Manufacturing Europe’s Future. Bruxelas: Bruegel Blueprint 21 